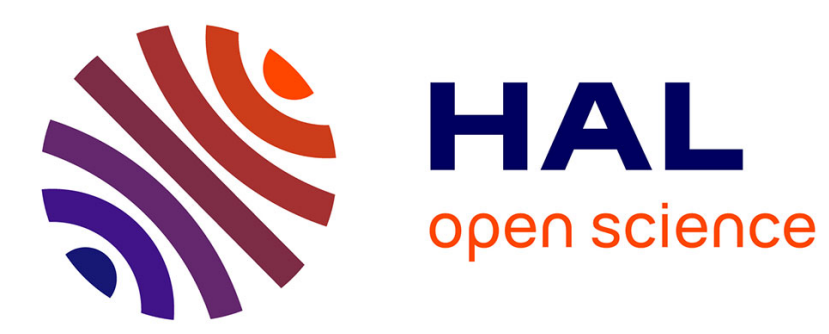

\title{
Branched polyethylene mimicry by metathesis copolymerization of fatty acid-based alpha,omega-dienes
} Thomas Lebarbé, Mehdi Neqal, Etienne Grau, Carine Alfos, Henri Cramail

\section{To cite this version:}

Thomas Lebarbé, Mehdi Neqal, Etienne Grau, Carine Alfos, Henri Cramail. Branched polyethylene mimicry by metathesis copolymerization of fatty acid-based alpha,omega-dienes. Green Chemistry, 2014, 16 (4), pp.1755-1758. 10.1039/c3gc42280a . hal-01366366

\section{HAL Id: hal-01366366 https://hal.science/hal-01366366}

Submitted on 22 Nov 2019

HAL is a multi-disciplinary open access archive for the deposit and dissemination of scientific research documents, whether they are published or not. The documents may come from teaching and research institutions in France or abroad, or from public or private research centers.
L'archive ouverte pluridisciplinaire HAL, est destinée au dépôt et à la diffusion de documents scientifiques de niveau recherche, publiés ou non, émanant des établissements d'enseignement et de recherche français ou étrangers, des laboratoires publics ou privés. 


\title{
Branched polyethylene mimicry by metathesis copolymerization of fatty acid- based $\alpha, \omega$-dienes.
}

\author{
Thomas Lebarbé, ${ }^{a, b, d}$ Mehdi Neqal, ${ }^{a, b}$ Etienne Grau, ${ }^{a, b}$ Carine Alfos, ${ }^{c}$ and Henri Cramail ${ }^{* a, b}$
}

Castor oil and vernonia oil platforms were used to synthesize two linear and branched $\alpha, \omega$-diene monomers. ADMET copolymerization conducted in bulk yielded a series of copolyesters with various degrees of branching with respect to the feed ratio between the two $\alpha, \omega$ dienes. After hydrogenation, these copolyesters showed thermo-mechanical properties in accordance with the ones of LLDPE and VLDPE with tunable melting points between $50^{\circ} \mathrm{C}$ and $90^{\circ} \mathrm{C}$. As expected and similarly to the "PE-like" polyesters reported in the 10 literature, the presence of ester functions distributed along the polyethylene backbone slightly lowered the crystalline ability of the soformed polyesters. Nevertheless, these novel bio-based polyesters constitute a good sustainable alternative to olefin-based elastomers (LLDPE and VLDPE), especially for specific applications which require degradability.

With about 80 million tons per year, polyethylene (PE) is the top manufactured polymer, giving rise to low cost materials. According to the type of polymerizations, various PE microstructures are achievable yielding materials with a large range of thermo-mechanical properties. Four types of PE are generally identified: almost purely linear high-density polyethylene (HDPE) (d 0.94-0.97 g.cm ${ }^{-3}$ ), low-density polyethylene (LDPE) (d 0.90-0.94 g.cm ${ }^{-3}$ ), linear low-density polyethylene (LLDPE) and very low-density polyethylene (VLDPE) (d 0.86-0.90 g.cm ${ }^{-3}$ ) which are characterized by different types and degrees of branching, randomly distributed along the polymer backbone. The presence of branches significantly lowers the crystalline ability of the PE, resulting in elastomeric and ductile mechanical features.

Despite the numerous applications of PE materials, the latter do not constitute a sustainable solution, in particular for environmental applications, as evidenced by their lack of hydrolytic degradability. With the aim to introduce potentially degradable segments to a PE backbone while keeping its characteristics, a lot of efforts have been carried out these last years to design sustainable and bio-based "polyethylene-like" polyesters. ${ }^{1-6}$ This is generally achieved by polycondensation of long-chain $\alpha, \omega$-difunctional monomers. In particular, many synthetic routes to the chemical modification (metathesis, thiolene addition, isomerizing alkoxycarbonylation...) of fatty acids were studied yielding long chain aliphatic monomers bearing hydroxyl, acid or ester groups.-9 After polymerization, aliphatic polyesters with variable ester function densities were obtained, as a function of the substrate and the chemical modification used. Nonetheless, most of the studies performed on the development of "PE-like" polyesters from fatty acids resulted in materials that mimic the structure of HDPE.

On the contrary, very few investigations were carried out to synthesize "LDPE-, LLDPE- and VLDPE-like" polyesters from plant oils. Some relevant examples include the works of Matsumura and coll. concerning the enzyme-catalysed copolymerizations of hydrogenated methyl ricinoleate (methyl 12-hydroxystearate) with 12-hydroxydodecanoic acid or pentadecalactone. ${ }^{10,11}$ By varying the feed ratio between the branched and linear monomers, a series of high molecular weight copolyesters with versatile properties were obtained.

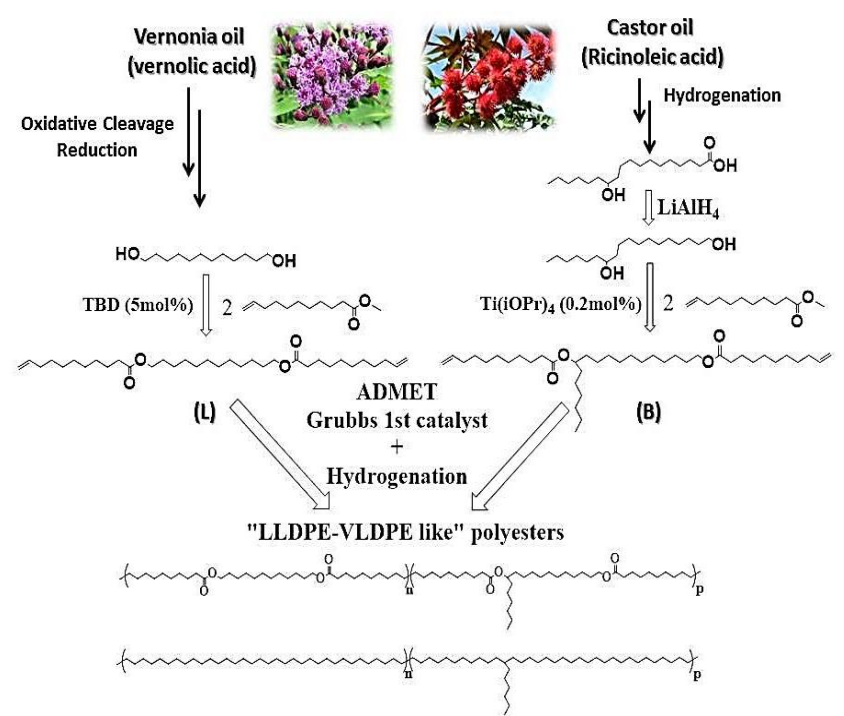

Figure 1- Synthetic strategy to "LLDPE like" polyesters

In this work, we aimed at developing new "LLDPE- and VLDPE-like" polyesters through acyclic diene metathesis (ADMET) copolymerization of two fatty-acid based $\alpha, \omega$-diene monomers. Castor oil and vernonia oil were used as feedstocks for the synthesis of the branched and linear monomers. ADMET copolymerization in bulk was then carried out yielding a series of copolyesters with various degrees of branching. Hydrogenation of the unsaturated copolyesters led to the saturated analogous mimicking the chemical structures of LLDPE and VLDPE (Figure 1). The thermo-mechanical properties of the so-formed copolyesters were investigated and compared to their petroleum-based analogues.

Methyl 10-undecenoate and 12-hydroxystearic acid, obtained by steam cracking and hydrogenation of ricinoleic acid respectively, were employed for the synthesis of the branched $\alpha, \omega$-diene (B). A second monomer (L) showing a linear structure (with the same main chain structure than for the branched monomer) was also synthesized from methyl 10undecenoate and 1,12-dodecanediol (obtained by oxidative cleavage of vernolic acid).

The formation of (L) was carried out by a simple transesterification, in bulk, of two equivalents of methyl 10undecenoate with one equivalent of 1,12-dodecanediol (Figure S2). For the branched monomer (B), the synthetic strategy was 
the same than for the linear one, using 12-hydroxystearyl alcohol instead of 1,12-dodecanediol (Figure S3). The polymerization grade of the monomers was confirmed by GC analysis regarding the high purity obtained (>97\%).

Once the $\alpha, \omega$-diene monomers $(\mathbf{L})$ and $(\mathbf{B})$ synthesized, it was then possible to develop a series of polyesters by ADMET copolymerization of the two monomers. All the polymerizations were launched at $85^{\circ} \mathrm{C}$ in bulk under dynamic vacuum due to the non-volatility of the monomers. Grubbs $1^{\text {st }}$ generation metathesis catalyst was employed in this study in order to limit olefins isomerization. The feed ratio between the two monomers was changed from $100 \%$ of purely linear monomer $(\mathbf{L})$ to $100 \%$ of branched monomer $(\mathbf{B})$ resulting in a number of atoms of the main chain between two branching points as low as 34 (0-29 branching points per 1000 atoms of the main chain) as shown in Table 1.

After $24 \mathrm{~h}$ of polymerization, the catalyst was deactivated with ethyl vinyl ether and the polyesters were precipitated into methanol. The resulting polyesters were analyzed both by ${ }^{1} \mathrm{H}-$ NMR and SEC in THF (Figure S4). The disappearance of the proton peaks at 5.8 and $4.9 \mathrm{ppm}$ and the appearance of a multiplet at $5.4 \mathrm{ppm}$ provide evidence of polyester synthesis by formation of internal olefins (Figure 2). The exact composition of the copolymers was also determined by ${ }^{1} \mathrm{H}-\mathrm{NMR}$ analysis. The average number of atoms of the main chain between two branching points was varying between 34 and 136 atoms (except for the purely linear polyester) which show good agreement with the number of carbon atoms generally found for commercial LLDPE.

The unsaturated polyesters were then analyzed by SEC in THF using a PS calibration. Except for B0 (62 kg. $\left.\mathrm{mol}^{-1}\right)$ synthesized using mechanical stirring (contrary to the other polyesters which were synthesized under magnetic stirring), the obtained molecular weight values were in the range $14-22 \mathrm{~kg} \cdot \mathrm{mol}^{-1}$ with Đ 1.5-1.7 (Table 1). Thus, mechanical stirring seems to be required for efficient removal of the ethylene condensate.

In certain circumstances, it is desirable to keep unsaturation in the polymer backbone for further functionalization or crosslinking. However, in the context of our study, the polyesters must be free from remaining double bonds to avoid oxidation and possible cross-linking during heating of the samples. Reduction of the double bonds of the polyesters proceeded in toluene at $80^{\circ} \mathrm{C}$ with $\mathrm{Pd}(10 \%)$ on charcoal under hydrogen pressure (50bar). Fully saturated polyesters were obtained as evidenced by the disappearance of olefins protons peaks in ${ }^{1} \mathrm{H}$ NMR spectra (Figure 2 and Figure S5). Only HB0 did not show quantitative conversion. It can be attributed to the lower solubility of the polyester. Nevertheless, a conversion of $88 \%$ was measured by ${ }^{1} \mathrm{H}-\mathrm{NMR}$ analysis for $\mathrm{HB} 0$ what should provide sufficient improvement of the thermo-mechanical properties.

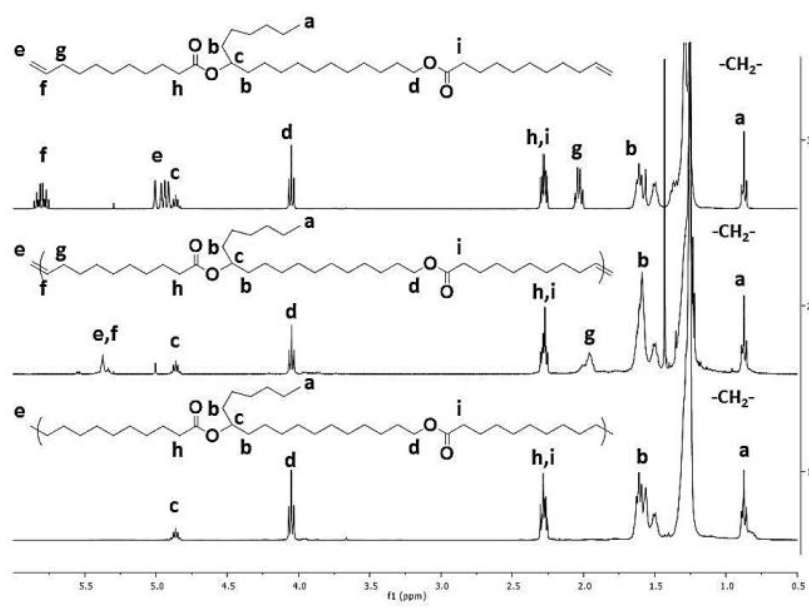

Figure 2- ${ }^{1} \mathrm{H}-\mathrm{NMR}$ stacked spectra of the branched $\alpha, \omega$-diene (up), B100 (middle) and HB100 (bottom) in $\mathrm{CDCl}_{3}$.

The thermal stability of the saturated polyesters was investigated by TGA experiments under non-oxidative atmosphere (Figure S6). High thermal stability for all polyesters was illustrated by the large difference $\left(>200^{\circ} \mathrm{C}\right)$ between their decomposition temperatures and their melting points, thus allowing easy compression or injection molding and therefore possible use for a wide range of applications.

In order to evaluate the influence of the degree of branching on the polyester crystallinity, DSC analyses were performed. The unsaturated polyesters were first analyzed. As show in Table 1 and Figure S7, hexyl branches significantly reduce the crystalline ability of the polyesters. Indeed both crystallization and melting temperatures (and their corresponding enthalpies) highly decrease with an increase in hexyl branches density. The unsaturated polyesters thus cover a large range of thermomechanical properties depending on the branching density with $\mathrm{Tm}$ in the range $13-69^{\circ} \mathrm{C}$. Melting enthalpy was also highly affected by the presence of hexyl branches with values equal to $34{\mathrm{~J} . \mathrm{g}^{-1}}^{1}$ and $101{\mathrm{~J} . \mathrm{g}^{-1}}^{-1}$ for $\mathrm{B} 100$ and B0 respectively. The relatively low value of melting point and corresponding enthalpy measured for B0 in comparison to other "PE-like" polyesters given in the literature is ascribed to the remaining olefins which disrupt efficient crystallites formation due to cisand trans- configurations and imped sufficient mobility of the chains. ${ }^{1}$

Hydrogenation of the unsaturated polyesters resulted in improved thermo-mechanical properties (Figure S8 and Figure 3). Indeed, the fully saturated structure of the resulting polyesters was responsible for improved chain packing and thus enhancement of the crystallization and melting temperatures (and their respective enthalpies). An enhancement of around $20-30^{\circ} \mathrm{C}$ was observed for the melting temperature of all the polyesters. 
Table 1- Thermo-mechanical properties of the unsaturated (B0-B100) and hydrogenated (HB0-HB100) polyesters.

\begin{tabular}{|c|c|c|c|c|c|}
\hline Entry & $\begin{array}{l}\text { mol\% } \\
(\mathbf{B})[\mathbf{d}]^{\mathrm{a}}\end{array}$ & $\begin{array}{c}\operatorname{Mn}[Ð] \\
\left(\mathbf{k g} \cdot \mathbf{m o l}^{-1}\right)^{\mathbf{b}}\end{array}$ & $\begin{array}{l}\mathbf{T}_{5 \%} \% \\
\left({ }^{\circ} \mathbf{C}\right)^{\mathbf{c}}\end{array}$ & $\operatorname{Tm}\left({ }^{\circ} \mathbf{C}\right)^{\mathrm{d}}$ & $\underset{\left(\mathbf{J J g}^{-1}\right)^{\mathbf{d}}}{\Delta \mathbf{H m}}$ \\
\hline o & \multirow{2}{*}{0} & \multirow{2}{*}{62 [1.5] } & & 68.9 & 101.2 \\
\hline HBO & & & 394 & 87.4 & 135.5 \\
\hline $\mathbf{B 2 5}$ & \multirow{2}{*}{22 [136] } & \multirow{2}{*}{20 [1.7] } & - & 55.9 & 89.4 \\
\hline HB25 & & & 357 & $59.2-77.0$ & 98.1 \\
\hline B50 & \multirow{2}{*}{47 [68] } & \multirow{2}{*}{22 [1.6] } & - & 46.3 & 62.9 \\
\hline HB50 & & & 344 & $44.8-64.9$ & 66.5 \\
\hline B75 & \multirow{2}{*}{74 [45] } & \multirow{2}{*}{$14[1.6]$} & - & $26.3-36.6$ & 38.1 \\
\hline HB75 & & & 331 & $51.3-56.6$ & 65.1 \\
\hline B100 & \multirow{2}{*}{100 [34] } & \multirow{2}{*}{22 [1.6] } & - & 13.2 & 32.4 \\
\hline HB100 & & & 312 & 51.6 & 63.0 \\
\hline
\end{tabular}

(a) ${ }^{1} \mathrm{H}-\mathrm{NMR}-[\mathrm{d}]$ is the branching density (number of atoms of the main chain between two branching points) (b) SEC in THF, PS calibration (c) TGA- $10^{\circ} \mathrm{C} \cdot \mathrm{min}^{-1}$ (d) DSC- $10^{\circ} \mathrm{C} \cdot \mathrm{min}^{-1}$

Despite the close average number of atoms between two branches in comparison to LLDPE (25-100 carbon atoms), the melting points of the branched polyesters (HB25, HB50, HB75 and $\mathrm{HB} 100)$ in the range $51-77^{\circ} \mathrm{C}$, were much lower than for LLDPE $\left(\mathrm{Tm} \sim 100-125^{\circ} \mathrm{C}\right)^{12-15}$ and were closer to those generally measured for VLDPE (Tm $\left.\sim 60-100^{\circ} \mathrm{C}\right)$. This deviation to the LLDPE thermo-mechanical properties was logically attributed to the presence of inherent ester functions, in accordance to the previous studies realized on "polyethylene like" polyesters. ${ }^{2-6,} 16$ Indeed, Penelle and coll. demonstrated that ester group can be incorporated in the crystallites thus lowering the overall attractive interactions between the polymer chains in comparison to polyethylene. ${ }^{17}$

It is noteworthy that only HB0 showed a narrow endothermic melting peak, while the other saturated polyesters showed complex melting patterns. This was attributed to the highly regular microstructure of $\mathrm{HB} 0$ in comparison to the other saturated polyesters for which hexyl branches are distributed randomly along the backbone, giving rise to a broader crystallite size distribution which impacts the melting temperature of the copolyesters. In the case of HB25 where the alkyl dangling chain density remains low, two narrow endothermic peaks were observed. To investigate this melting behavior, DSC analysis was performed on a HB25 sample annealed for 15 minutes at $65^{\circ} \mathrm{C}$ (temperature between the two endothermic peaks). The obtained DSC heating trace (Figure S9) showed evidence of two distinct melting peaks at similar temperatures than without annealing. This information let us consider polymorphism (different crystalline phases or crystallites differing in size) rather than melting of a metastable crystalline phase with subsequent crystallization into a more stable phase.

Modulated DSC analysis at a heating rate of $3^{\circ} \mathrm{C} \cdot \mathrm{min}^{-1}$ was then performed on the same sample (HB25). Indeed, the DSC traces, displayed in Figure S10 gives evidence of polymorphism. Indeed, the reversible heat flow signal shows two endothermic peaks with maxima at $59^{\circ} \mathrm{C}$ and $78^{\circ} \mathrm{C}$ related to two melting transitions. On the contrary, the non-reversible heat flow shows no significant variations (crystallization) in the temperature window concerned. Thus, the complex melting pattern is not ascribed to a melting-recrystallization process but to polymorphism.

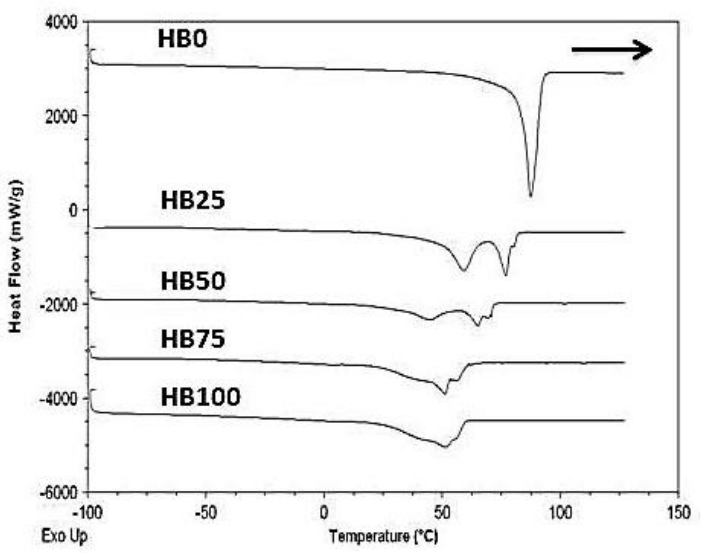

Figure 3- DSC heating curves of the saturated polyesters. $10^{\circ} \mathrm{C} \cdot \mathrm{min}^{-1}$.

It is known that, contrary to ethylene/propylene copolymers, ethylene/octene copolymers display the exclusion of large hexyl branches from the crystal unit cell. ${ }^{12,18}$ In the case of HB25 and HB50, due to the low branching density and the randomness of the branching point positions along the polyester backbone, it is thought that the melting peak at lower temperature is assigned to crystallites corresponding to segments with high branching content (smaller crystallites). The melting transition at higher temperature corresponds to the nearly linear segments. This hypothesis was confirmed by wide-angle X-ray diffraction (WAXD) performed on HB0 and HB25. From the WAXD patterns (Figure S11) obtained at $25^{\circ} \mathrm{C}$, HB0 displays the same typical orthorhombic crystal structure than HDPE (lattice parameters $a=7.40 \AA, b=4.93 \AA$ and $c=2.54 \AA$ ) with two characteristic crystalline peaks at scattering angles of $21.6^{\circ}$ and $24.0^{\circ}$ corresponding to reflection planes (110) and (200) respectively. ${ }^{19},{ }^{20}$ Regarding HB25, the insignificant change in the scattering angle values $\left(21.5^{\circ}\right.$ and $23.8^{\circ}$ ) in comparison to HB0 provides evidence of the orthorhombic crystal structure too. Moreover, no other peaks were observed for HB25, which suggests the existence of only one crystal structure despite the presence of the hexyl branches. This feature clearly shows that the melting transition occurring at lower temperature is ascribed to the melting of crystallites of smaller sizes. It was fully confirmed by the apparent crystallite sizes calculated using Scherrer equation both at $25^{\circ} \mathrm{C}$ or $60^{\circ} \mathrm{C}$ (Table S2 and Figure S12). ${ }^{21}$

\section{Conclusion}

Castor oil platform was efficiently used to develop a series of "LLDPE-like" polyesters by ADMET polymerization. Two biobased $\alpha, \omega$-diene monomers, one linear and one bearing an hexyl dangling chain, were first synthesized. The $\alpha, \omega$-dienes were then copolymerized in different amounts resulting in unsaturated polyesters covering a wide range of thermomechanical properties. Their hydrogenation yielded the saturated polyesters that showed close structural similarities 
with LLDPE regarding their polyethylene backbone with incorporated ester functions and hexyl dangling chains. These copolyesters showed good thermal stability as seen from the initial degradation temperatures above $300^{\circ} \mathrm{C}$. Thermomechanical properties were closer to VLDPE than LLDPE regarding the melting points in the range $51-77^{\circ} \mathrm{C}$. For most of the copolyesters, a broad melting peak with complex pattern was observed which provide evidence of small crystallites formation with a high heterogeneity in size. These novel biobased materials, constitute good sustainable alternatives to petroleum-based LLDPE and VLDPE. Indeed, these copolyesters were synthesized by ADMET approach under mild conditions (bulk process and moderate temperatures) using bio-based monomers obtained from non-edible and annually plant oils derivatives. Moreover, the incorporation of hydrolysable ester functions along the polyethylene backbone let us consider biomedical and environmental applications for these new materials thanks to their potential biodegradability.

\section{Acknowledgements}

The authors thank Ahmed Bentaleb (CRPP-CNRS) for the WAXD measurements. This study was financially supported by the University of Bordeaux-1, ANR, IPB, CNRS, Aquitaine Council, ITERG, ONIDOL and ADEME agency.

\section{Notes}

${ }^{a}$ Univ. of Bordeaux, Laboratoire de Chimie des Polymères Organiques, UMR 5629, IPB/ENSCBP, 16 avenue Pey-Berland, F-33607, Pessac cedex, France

${ }^{b}$ Centre National de la Recherche Scientifique, Laboratoire de Chimie des Polymères Organiques, UMR 5629, F-33607, Pessac, France, Email :cramail@enscbp.fr

'ITERG, 11 rue Gaspard Monge, Parc Industriel, F-33600, Pessac, France.

${ }^{d}$ French Environment and Energy Management Agency, 20 avenue du Grésillé-BP 90406, F-49004, Angers Cedex 01, France

\section{References}

1. J. Trzaskowski, D. Quinzler, C. Bährle and S. Mecking, Macromolecular Rapid Communications, 2011, 32, 1352-1356.

2. F. Stempfle, D. Quinzler, I. Heckler and S. Mecking, Macromolecules, 2011, 44, 4159-4166.

3. C. Vilela, A. J. D. Silvestre and M. A. R. Meier, Macromolecular Chemistry and Physics, 2012, 213, 2220-2227.

4. F. Stempfle, P. Ortmann and S. Mecking, Macromolecular Rapid Communications, 2013, 34, 47-50.

5. M. P. F. Pepels, M. R. Hansen, H. Goossens and R. Duchateau, Macromolecules, 2013, 46, 7668-7677.

6. P. Ortmann and S. Mecking, Macromolecules, 2013, 46, 72137218.

7. L. Maisonneuve, T. Lebarbe, E. Grau and H. Cramail, Polymer Chemistry, 2013, 4, 5472-5517.

8. L. Montero de Espinosa and M. A. R. Meier, European Polymer Journal, 2011, 47, 837-852.

9. U. Biermann, U. Bornscheuer, M. A. R. Meier, J. O. Metzger and H. J. Schäfer, Angewandte Chemie International Edition, 2011, 50, 3854-3871.

10. H. Ebata, K. Toshima and S. Matsumura, Macromolecular Bioscience, 2008, 8, 38-45.

11. T. Kobayashi and S. Matsumura, Polymer Degradation and Stability, 2011, 96, 2071-2079.
12. R. G. Alamo and L. Mandelkern, Thermochimica Acta, 1994, 238, 155-201.

13. R. G. Alamo, B. D. Viers and L. Mandelkern, Macromolecules, 1993, 26, 5740-5747.

14. R. G. Alamo and L. Mandelkern, Macromolecules, 1989, 22, 1273-1277.

15. R. Alamo, R. Domszy and L. Mandelkern, The Journal of Physical Chemistry, 1984, 88, 6587-6595.

16. I. van der Meulen, E. Gubbels, S. Huijser, R. 1. Sablong, C. E. Koning, A. Heise and R. Duchateau, Macromolecules, 2011, 44, 4301-4305.

17. C. L. F. De Ten Hove, J. Penelle, D. A. Ivanov and A. M. Jonas, Nat Mater, 2004, 3, 33-37.

18. M. J. Richardson, P. J. Flory and J. B. Jackson, Polymer, 1963, 4, 221-236.

19. M. F. Butler, A. M. Donald, W. Bras, G. R. Mant, G. E. Derbyshire and A. J. Ryan, Macromolecules, 1995, 28, 6383-6393.

20. Y.-L. Hsieh and X.-P. Hu, Journal of Polymer Science Part B: Polymer Physics, 1997, 35, 623-630.

21. P. Scherrer, Göttinger Nachrichten Math. Phys., 1918, 2, 98-100. 


\section{Supporting Information}

\section{Branched polyethylene mimicry by metathesis copolymerization of fatty acid-based $\alpha, \omega$-dienes.}

Thomas Lebarbé, ${ }^{a, b, d}$ Mehdi Neqal, ${ }^{a, b}$ Etienne Grau, ${ }^{a, b}$ Carine Alfos,${ }^{c}$ and Henri Cramail ${ }^{a, b, *}$

\section{Materials and Instrumentation}

Methyl 10-undecenoate (>98.0\%) was supplied by TCI Europe. 1,5,7-triazabicyclo[4.4.0]dec5-ene (TBD, 98\%), Grubbs $1^{\text {st }}$ generation metathesis catalyst, ethyl vinyl ether (99\%), titanium isopropoxide (99.9\%), 1,12-dodecanediol (99\%), lithium hydroxide (98\%), lithium aluminium hydride (95\%), palladium (10\%) on charcoal were obtained from Sigma-Aldrich. 12-hydroxy stearic acid (99\%) was purchased from Nu-Chek Prep (US).

All NMR experiments were performed at $298 \mathrm{~K}$ on a Bruker Avance I NMR spectrometer operating at $400 \mathrm{MHz}$ and equipped with a Bruker multinuclear z-gradient direct probe head capable of producing gradients in the $\mathrm{z}$ direction with strength 53.5 G.cm ${ }^{-1}$. Size exclusion chromatography (SEC) analyses were performed in THF $\left(40^{\circ} \mathrm{C}\right)$ on a PL-GPC 50 plus Integrated GPC from Polymer laboratories-Varian with a series of four columns from TOSOH (TSKgel TOSOH: HXL-L (guard column 6,0mm ID x 4,0cm L); G4000HXL (7,8mm ID x 30,0cm L); G3000HXL (7,8mm ID x 30,0cm L) and G2000HXL (7,8mm ID x 30,0 cm L)). The elution of the filtered samples was monitored using simultaneous refractive index and UV detection. The elution times were converted to molar mass using a calibration curve based on low dispersity $\left(\mathrm{M}_{\mathrm{w}} / \mathrm{M}_{\mathrm{n}}\right)$ polystyrene (PS) standards. Differential scanning calorimetry (DSC) thermograms were measured using a DSC Q100 apparatus from TA instruments. Polymer samples were first heated from $-100^{\circ} \mathrm{C}$ to $130^{\circ} \mathrm{C}$, subsequently cooled from $130^{\circ} \mathrm{C}$ to $-100^{\circ} \mathrm{C}$ and then the melting points were calculated from a second heating run. All runs were performed at a rate of $10{ }^{\circ} \mathrm{C} \cdot \mathrm{min}^{-1}$. Modulated DSC analyses were done from $-100^{\circ} \mathrm{C}$ to 
$100^{\circ} \mathrm{C}$ after the sample was kept at $100^{\circ} \mathrm{C}$ for 3 minutes to erase the thermal history of the polymer. The analysis was performed at a rate of $3^{\circ} \mathrm{C} \cdot \mathrm{min}^{-1}$ with a modulation amplitude of $0.64{ }^{\circ} \mathrm{C}$ and a modulation period of $60 \mathrm{~s}$. Thermogravimetric analyses (TGA) were performed on TGA-Q50 system from TA instruments at a heating rate of $10{ }^{\circ} \mathrm{C} \cdot \mathrm{min}^{-1}$ under nitrogen atmosphere from $\mathrm{RT}$ to $700^{\circ} \mathrm{C}$. X-ray diffraction patterns at wide angles (WAXS) were obtained with a microfocus rotating anode X-ray source giving radiation of $1.5418 \AA$ (Rigaku MicroMax-007 HF) combined with performant multi-layers optics and a 3-pinholes collimation that provide an intense X-ray intensity on the sample. The sample, mounted on XY stage, was held in a Lindemann capillary and placed in an oven providing a temperature control of $0.1 \mathrm{~K}$. A 2-dimensionnal detector (Image plate from Mar Research) was collecting the scattered radiations. Calibration of the sample-detector distance was performed using silver behenate as a reference.

\section{Synthesis of monomers}

Linear a, $\omega$-diene monomer $(\boldsymbol{L})$. Compound (L) was prepared using methyl 10-undecenoate $(15 \mathrm{~g}, 75.6 \mathrm{mmol})$ as two molar equivalents and 1,12-dodecanediol (7.65g, $37.8 \mathrm{mmol})$, representing one equivalent in terms of reactive functions. The reaction was catalyzed by Triazabicyclodecene (TBD) using a 5\% mol ratio regarding 10-methylundecenoate. The mixture was flushed with nitrogen at $120^{\circ} \mathrm{C}$ for $6 \mathrm{~h}$. Then, for the last $2 \mathrm{~h}$, the nitrogen flux was substituted for vacuum. The reaction was eventually stopped and the compound was isolated by (recrystallization at $50^{\circ} \mathrm{C}$ in dichloromethane) and then on silica-gel column eluted with a mixture of cyclohexane/ethyl acetate (80/20). The process resulted in the isolation of compound (L) as a white solid in $61 \%$ yield $(12.4 \mathrm{~g})$.

Branched a, $\omega$-diene monomer $(\boldsymbol{B})$. The 12-hydroxy stearyl alcohol first had to be reduced from its carboxylic acid version, the 12-hydroxy stearic acid. This reaction was carried out using $10 \mathrm{~g}$ (33 mmol) of 12-hydroxy stearic acid and 3 molar equivalents of $\mathrm{LiAlH}_{4}(3.79 \mathrm{~g}$, 
$100 \mathrm{mmol}$ ) catalyst. The 12-hydroxy stearic acid was first dissolved in $100 \mathrm{~mL}$ of dry THF, and $\mathrm{LiAlH}_{4}$ was slowly dissolved in $300 \mathrm{~mL}$. The reaction flask with $\mathrm{LiAlH}_{4}$ was put in an ice bath and the dissolved 12-hydroxy stearic acid was slowly added. The mixture was stirred for $16 \mathrm{~h}$ under nitrogen, then the ice bath was removed and the mixture was refluxed at $70^{\circ} \mathrm{C}$ for $6 \mathrm{~h}$. Distilled water was added to deactivate the remaining hydride followed by $400 \mathrm{~mL}$ of $1 \mathrm{~N}$ $\mathrm{HCl}$. The synthesized compound could not be isolated using a silica-gel column, whatever the solvents or the proportions involved. The 12-hydroxystearic acid was separated from the 12hydroxystearyl alcohol using Lithium hydroxide in THF. 12-hydroxystearic acid precipitated by forming a complex with the lithium ion whilst on carboxylate form. The 12-hydroxystearyl alcohol is still soluble in THF and can be isolated by simple filtration. Then, compound (B) was synthesized by transesterification using 10-methylundecenoate ( $6.39 \mathrm{~g}, 32.2 \mathrm{mmol})$ as 2.5 molar equivalents and 12-hydroxystearyl alcohol (4.37 $\mathrm{g}, 12.9 \mathrm{mmol})$ as one molar equivalent. The same conditions were used for the reaction than for compound (L) except the catalyst which was substituted by $0.2 \mathrm{~mol} \%$ of titanium isopropoxide. Compound (B) was isolated using silica-gel column eluted with a mixture of n-heptane/ethyl acetate (95/5). The process resulted in the isolation of compound (B) as a viscous liquid with a $99 \%$ purity determined by gas chromatography.

\section{Polymerization reactions}

The copolymers were synthesised by ADMET polymerization using monomers $(\mathbf{B})$ and $(\mathbf{L})$ in various amounts. Each reaction was catalyzed using first generation Grubbs metathesis catalyst at $1 \mathrm{~mol} \%$. The reaction was carried out at $85^{\circ} \mathrm{C}$ for $8 \mathrm{~h}$, and vacuum was constantly applied to remove the ethylene formed during the polymerization. The reaction medium was then solubilized in THF and deactivated using ethylvinyl ether. ${ }^{1} \mathrm{H}-\mathrm{NMR}$ and SEC (in THF) analyses of the resulting polymers showed almost quantitative conversion of the monomers as evidenced by the absence of corresponding peaks (terminal olefins in 1H-NMR) and traces (in SEC). Each polymer was then precipitated in methanol and dried to remove solvent traces. 


\section{Hydrogenation of the polyesters}

Unsaturations in between polymer units were hydrogenated by solubilizing each polymer in toluene with a $15 \mathrm{~mL}$ ratio for $500 \mathrm{mg}$ of polymer. The Palladium on charcoal catalyst was added with a $50 \mathrm{mg}$ ratio for $500 \mathrm{mg}$ of polymer. The reaction was carried out under $50 \mathrm{bar}$ $\mathrm{H}_{2}$ at $80^{\circ} \mathrm{C}$ for $20 \mathrm{~h}$. The resulting solution was filtered on Celite to isolate the saturated polymer after removal of the solvent under reduced pressure.

\section{Additional tables and figures}

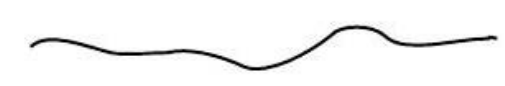

High-Density Polyethylene (HDPE) $\mathrm{Xc} \sim 55-77 \% \quad \mathrm{Tm} \sim 125-132^{\circ} \mathrm{C}$

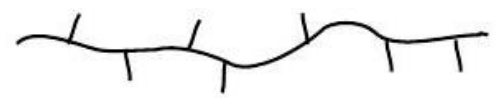

Linear Low-Density Polyethylene (LLDPE)

Branching density 25-100 C atoms $\mathrm{Xc} \sim 22-55 \% \quad \mathrm{Tm} \sim 100-125^{\circ} \mathrm{C}$

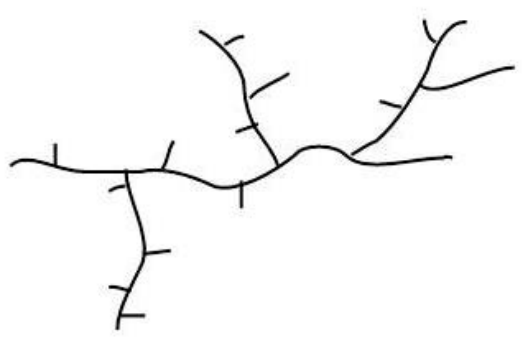

Low-Density Polyethylene (LDPE) $\mathrm{Xc} \sim 30-54 \% \quad \mathrm{Tm} \sim 98-115^{\circ} \mathrm{C}$

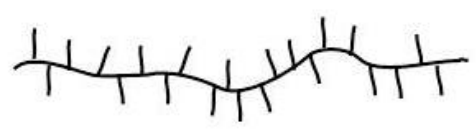

Very Low-Density Polyethylene (VLDPE)

Branching density 7-25 C atoms $\mathrm{Xc} \sim 0-22 \% \mathrm{Tm} \sim 60-100^{\circ} \mathrm{C}$

Figure S1- Schematic representation of polyethylene classes and corresponding properties 


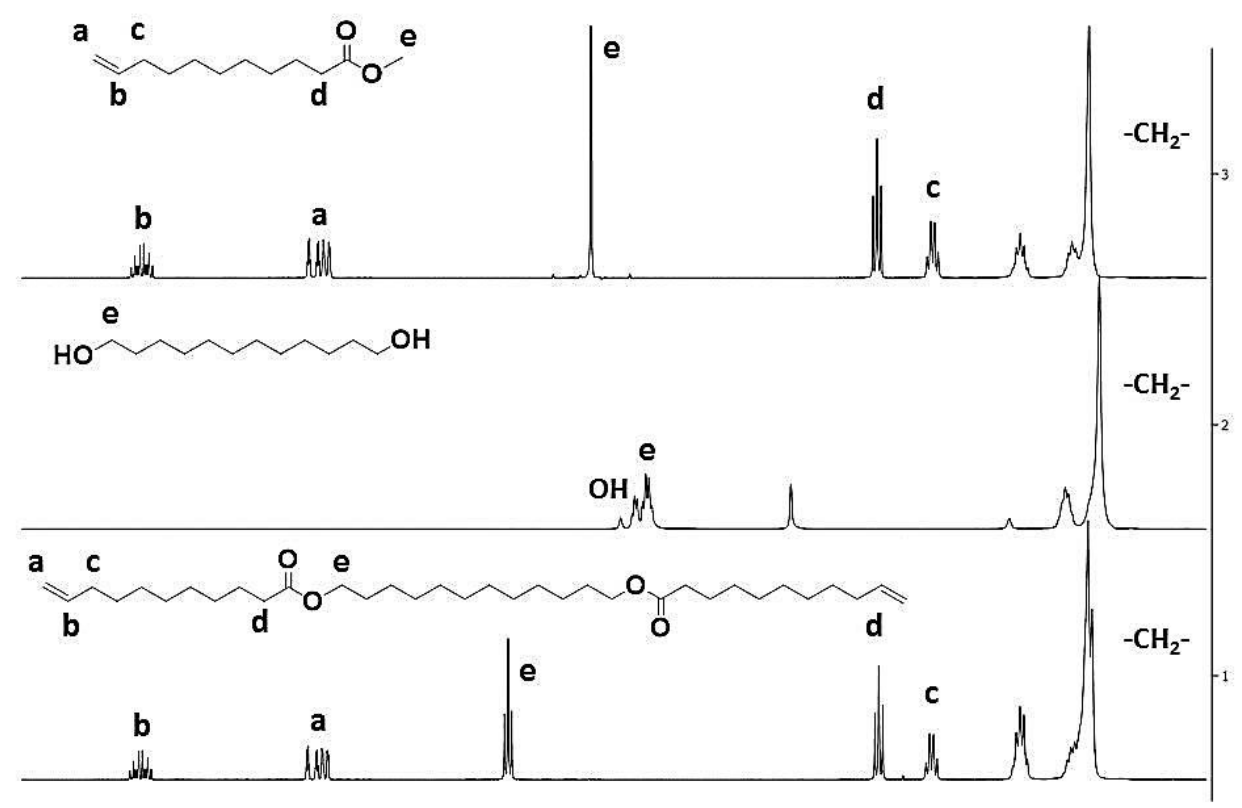

$\begin{array}{llllllllllllllllllllllllllll}6.2 & 6.0 & 5.8 & 5.6 & 5.4 & 5.2 & 5.0 & 4.8 & 4.6 & 4.4 & 4.2 & 4.0 & 3.8 & \begin{array}{c}3.6 \\ \mathrm{f} 1(\mathrm{ppm})\end{array} & 3.2 & 3.0 & 2.8 & 2.6 & 2.4 & 2.2 & 2.0 & 1.8 & 1.6 & 1.4 & 1.2 & 1.0 & 0.8\end{array}$

Figure S2- ${ }^{1} \mathrm{H}-\mathrm{NMR}$ stacked spectra of methyl 10-undecenoate $\left(\mathrm{CDCl}_{3}\right)$, 1,12-dodecanediol $\left(\mathrm{DMSO}-\mathrm{d}_{6}\right)$ and linear $\alpha, \omega$-diene $\left(\mathrm{CDCl}_{3}\right)$.

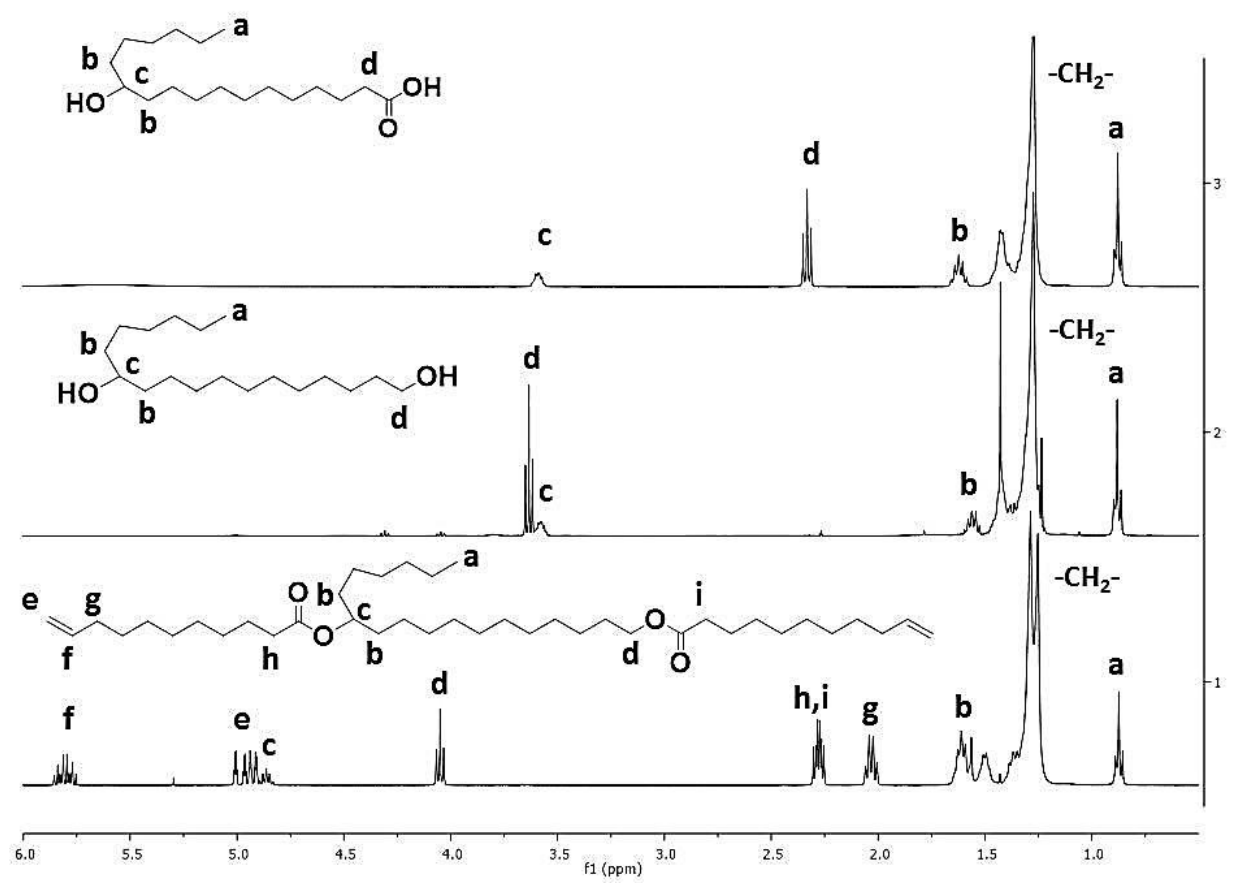

Figure S3- ${ }^{1} \mathrm{H}-\mathrm{NMR}$ stacked spectra of 12-hydroxystearic acid, 12-hydroxystearyl alcohol and branched $\alpha, \omega$-diene in $\mathrm{CDCl}_{3}$. 


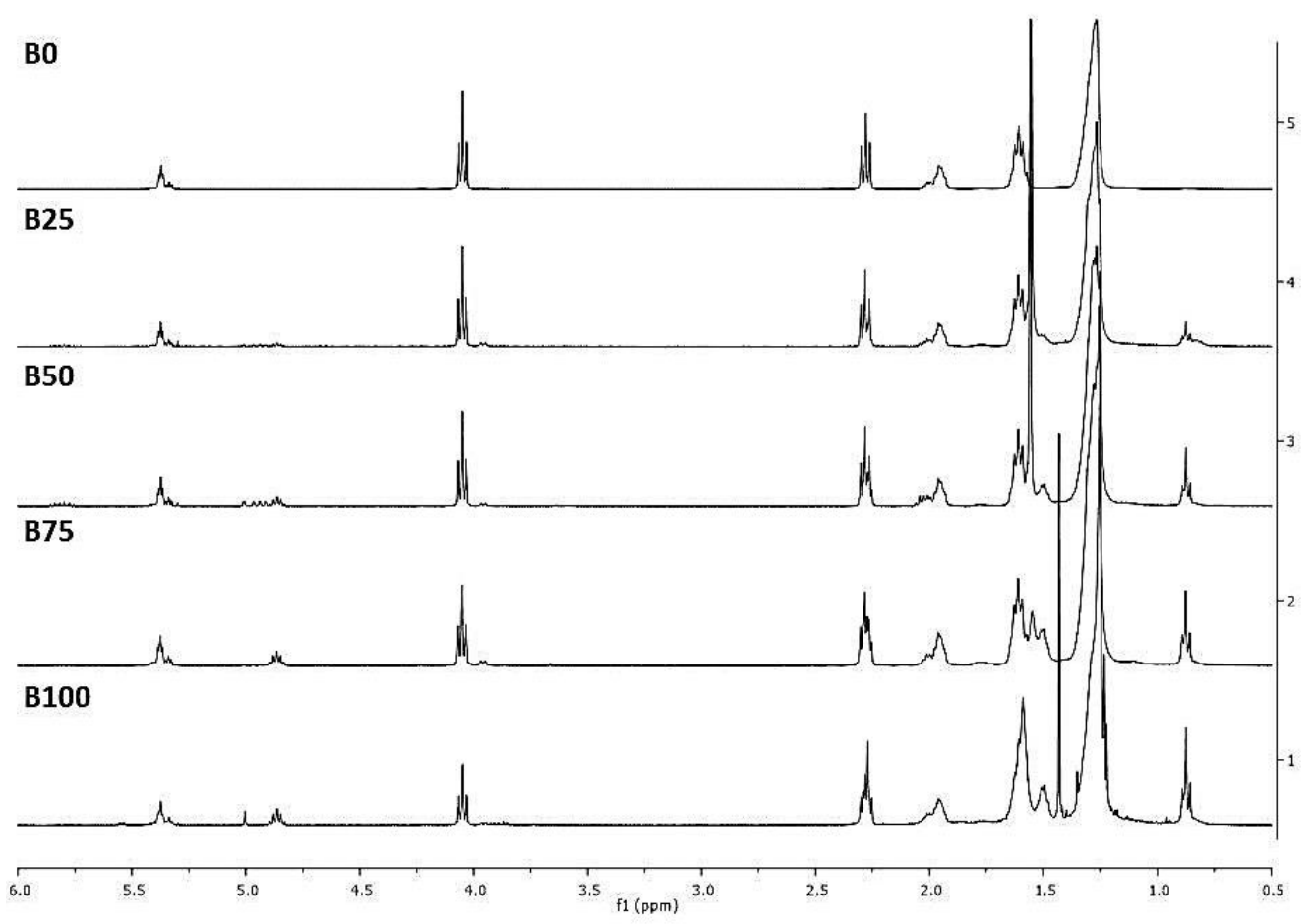

Figure S4- ${ }^{1} \mathrm{H}-\mathrm{NMR}$ stacked spectra of the unsaturated polyesters in $\mathrm{CDCl}_{3}$.

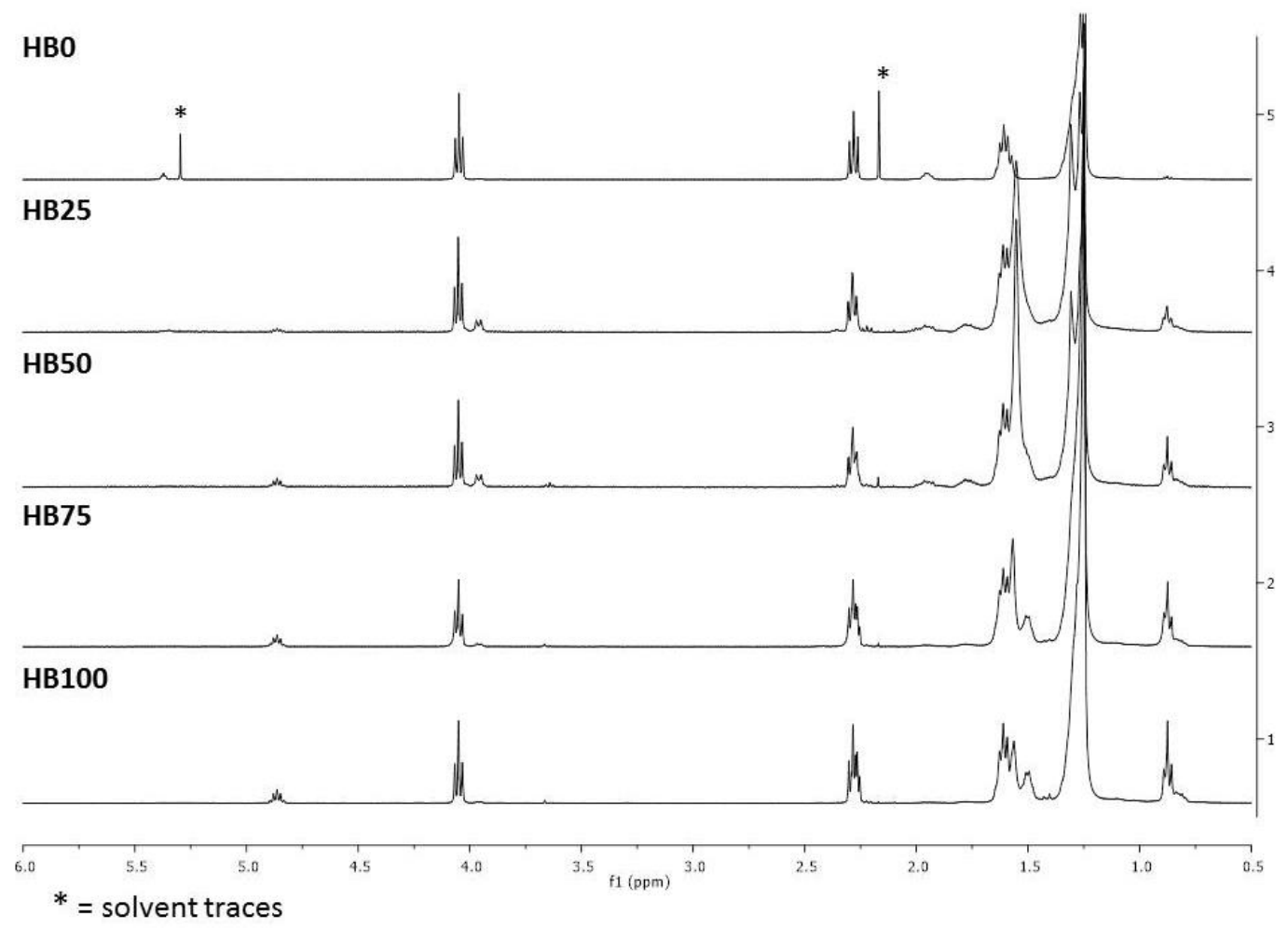

Figure S5- ${ }^{1} \mathrm{H}-\mathrm{NMR}$ stacked spectra of the hydrogenated polyesters in $\mathrm{CDCl}_{3}$. 

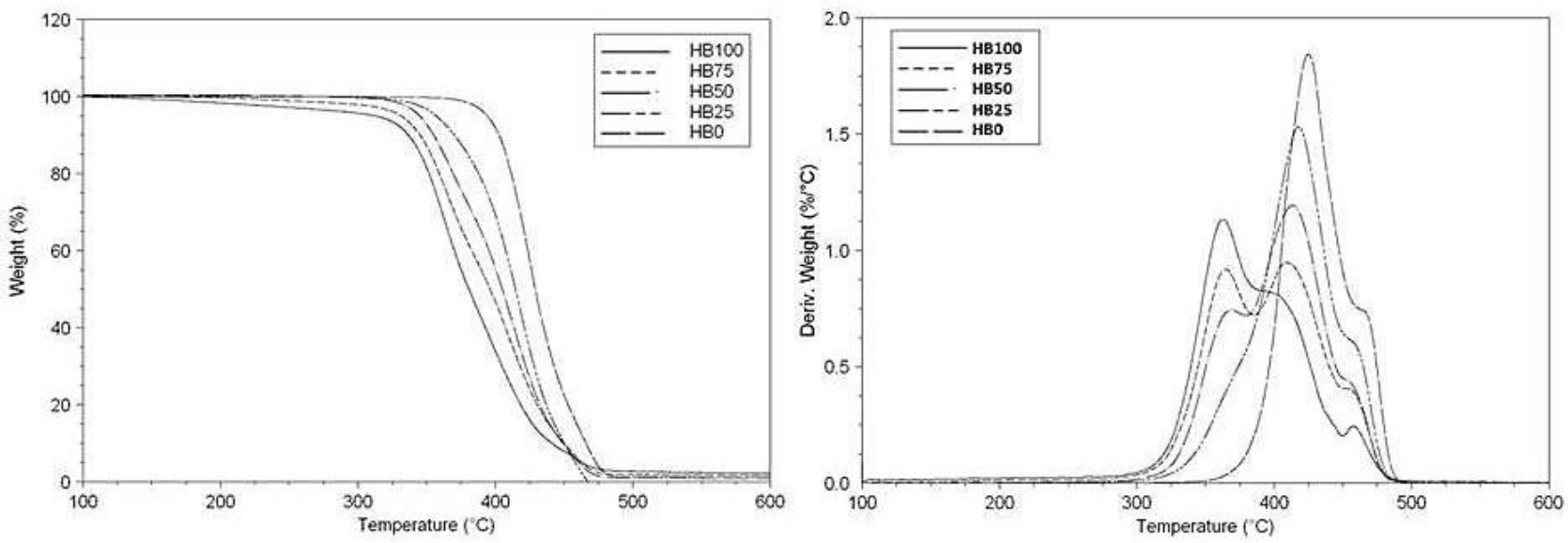

Figure S6- TGA curves and derivative curves of the saturated polyesters. $10^{\circ} \mathrm{C} \cdot \mathrm{min}^{-1}$.
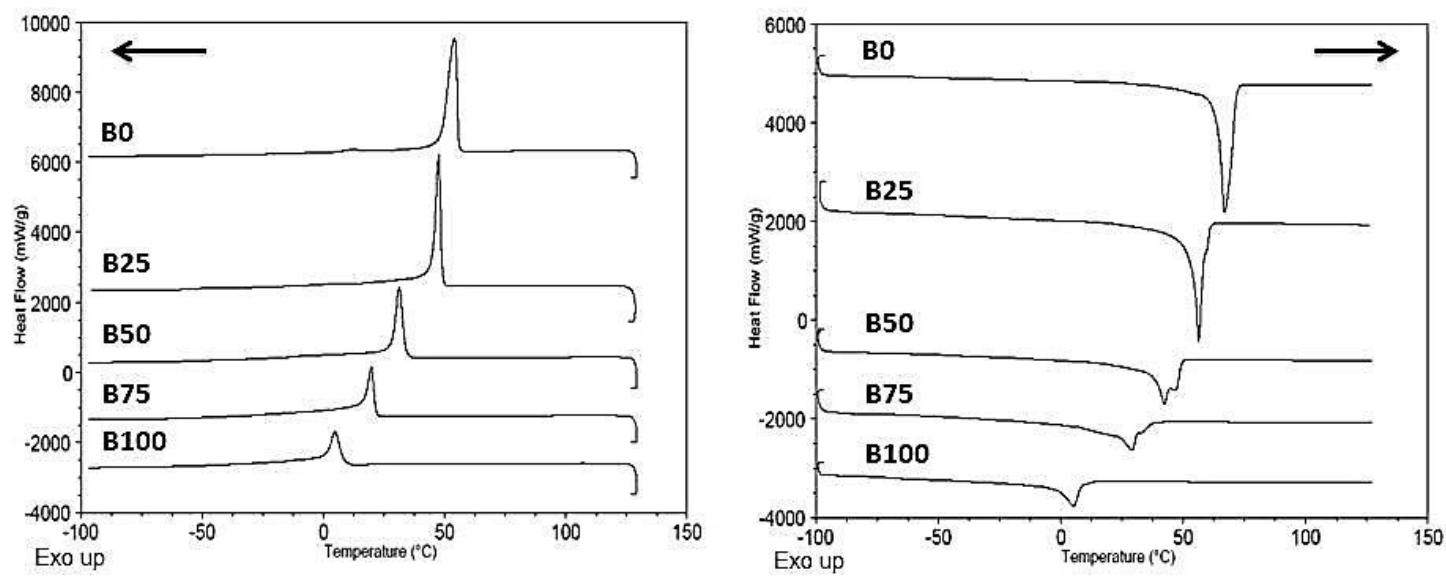

Figure S7- DSC cooling and heating curves of the unsaturated polyesters. $10^{\circ} \mathrm{C} \cdot \mathrm{min}^{-1}$.

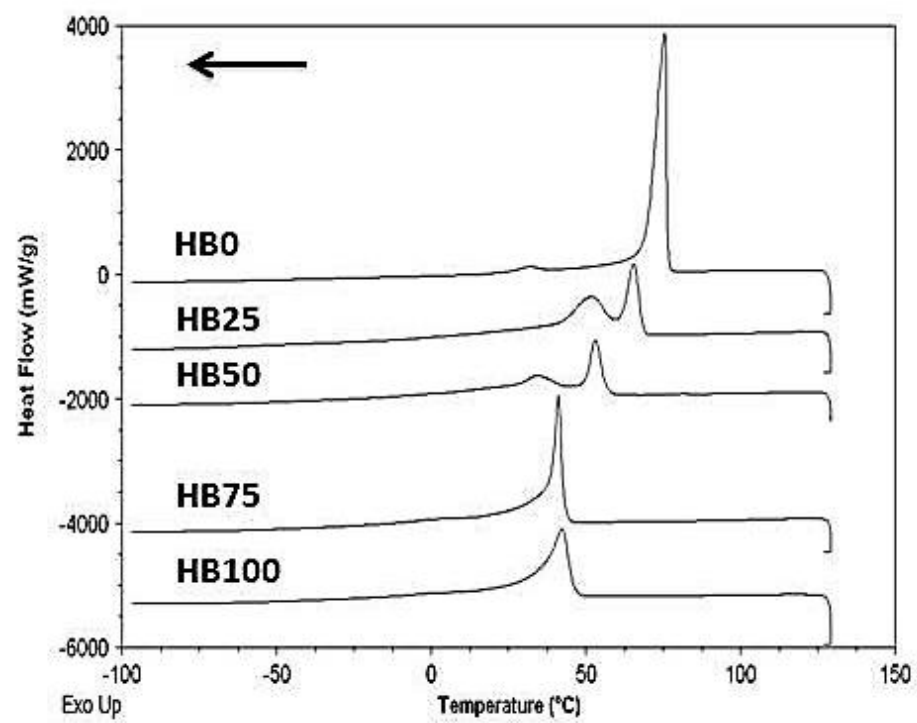

Figure S8- DSC cooling curves of the hydrogenated polyesters. $10^{\circ} \mathrm{C} \cdot \mathrm{min}^{-1}$. 
Table S1- Crystallization parameters of the unsaturated and the hydrogenated copolyesters.

\begin{tabular}{cccc} 
Entry & mol\% $(\mathbf{B})[\mathbf{d}]^{\mathbf{a}}$ & $\mathbf{T c}\left({ }^{\circ} \mathbf{C}\right)^{\mathbf{b}}$ & $\Delta \mathbf{H c}\left(\mathbf{J . g}^{-\mathbf{1}}\right)^{\mathbf{b}}$ \\
\hline B0 & \multirow{2}{*}{0} & 54.0 & 103.3 \\
HB0 & & 75.4 & 133.3 \\
\hline B25 & \multirow{2}{*}{$22[136]$} & 47.6 & 88.4 \\
HB25 & & $51.3-65.5$ & 92.6 \\
\hline B50 & \multirow{2}{*}{$47[68]$} & 31.2 & 62.3 \\
HB50 & & $34.1-53.2$ & 65.3 \\
\hline B75 & \multirow{2}{*}{$74[45]$} & 19.7 & 40.1 \\
HB75 & & 41.0 & 62.9 \\
\hline B100 & \multirow{2}{*}{$100[34]$} & 4.9 & 32.1 \\
HB100 & & 42.2 & 60.3
\end{tabular}

(a) ${ }^{1} \mathrm{H}-\mathrm{NMR}-[\mathrm{d}]$ is the branching density (number of atoms of the main chain between two branching points) (b) DSC$10^{\circ} \mathrm{C} \cdot \mathrm{min}^{-1}$

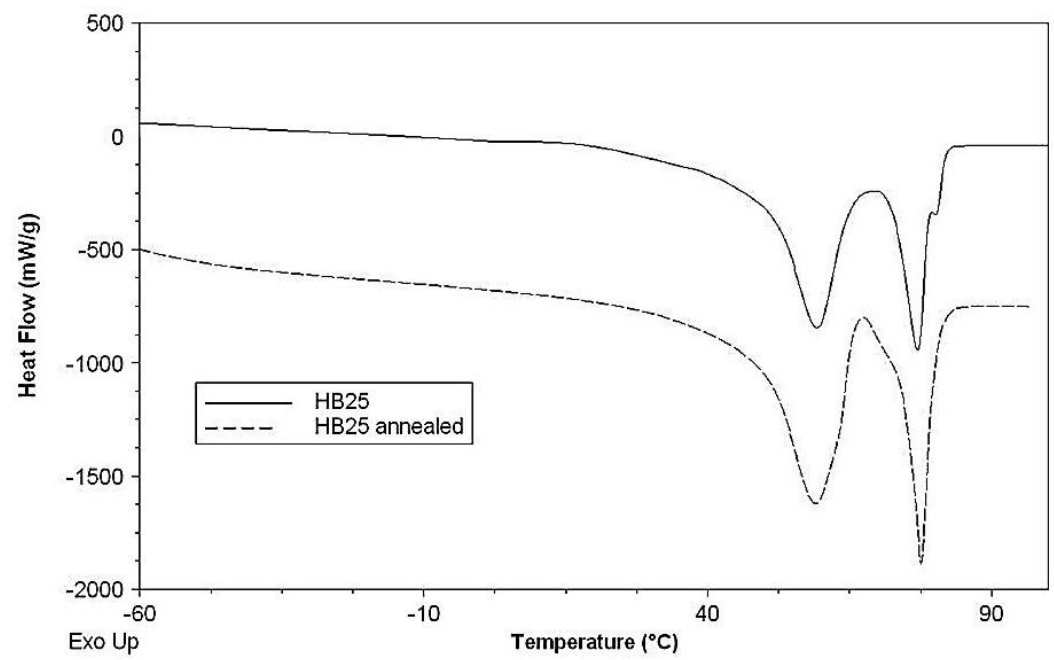

Figure S9- DSC heating scan traces of $\mathrm{HB} 25$ before and after annealing at $65^{\circ} \mathrm{C}$ during 15 minutes. $10^{\circ} \mathrm{C} \cdot \mathrm{min}^{-1}$.

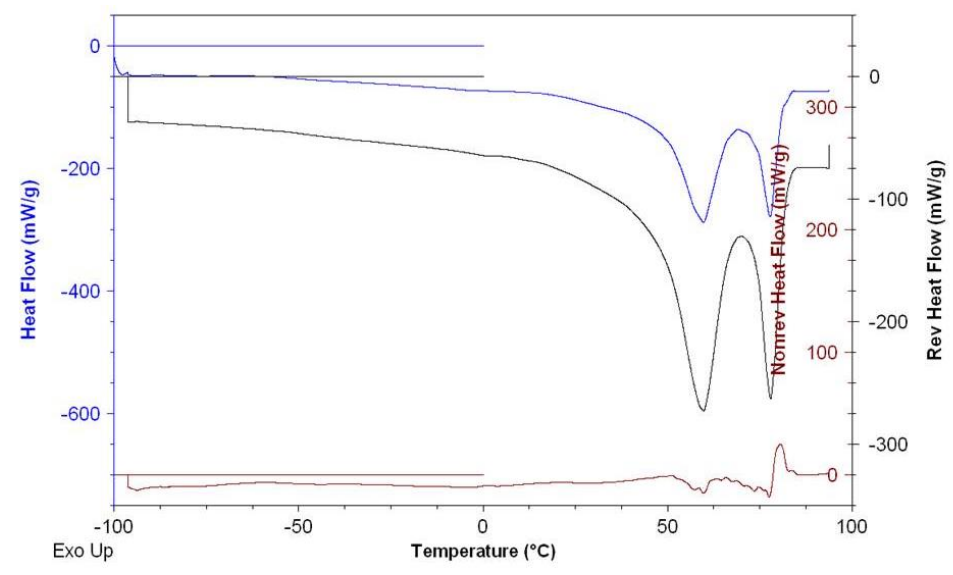

Figure S10- Modulated DSC heating scan traces of HB25. $3^{\circ} \mathrm{C} \cdot \mathrm{min}^{-1}$. 


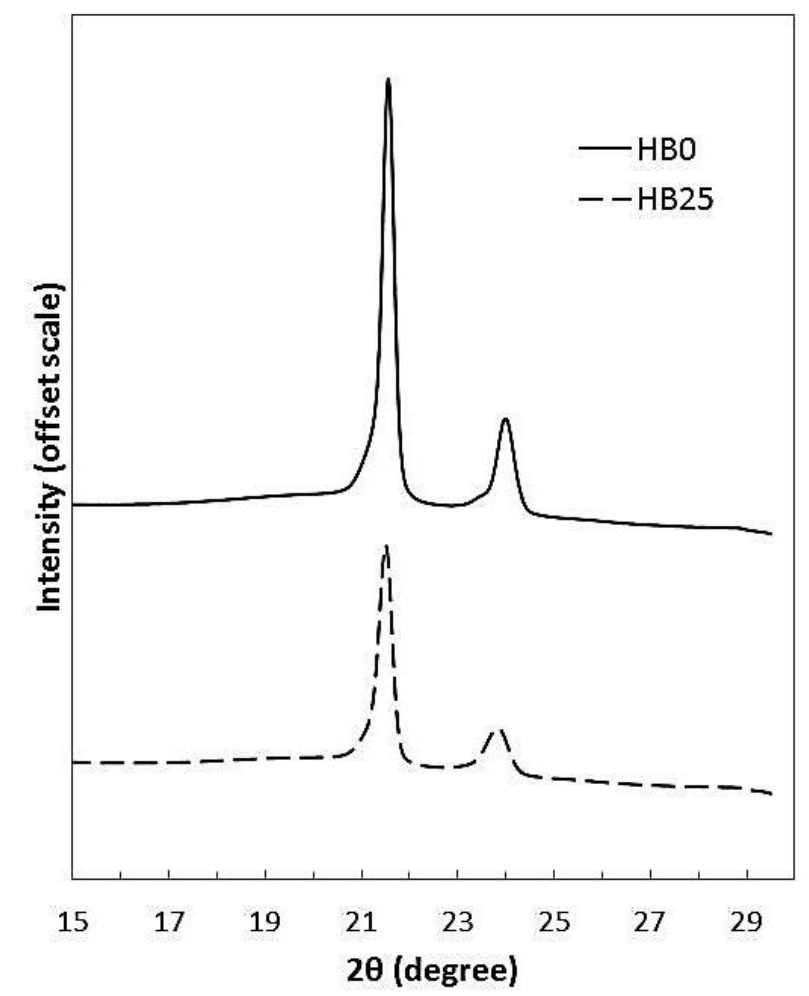

Figure S11- WAXD patterns of HB0 and HB25 obtained at $25^{\circ} \mathrm{C}$.

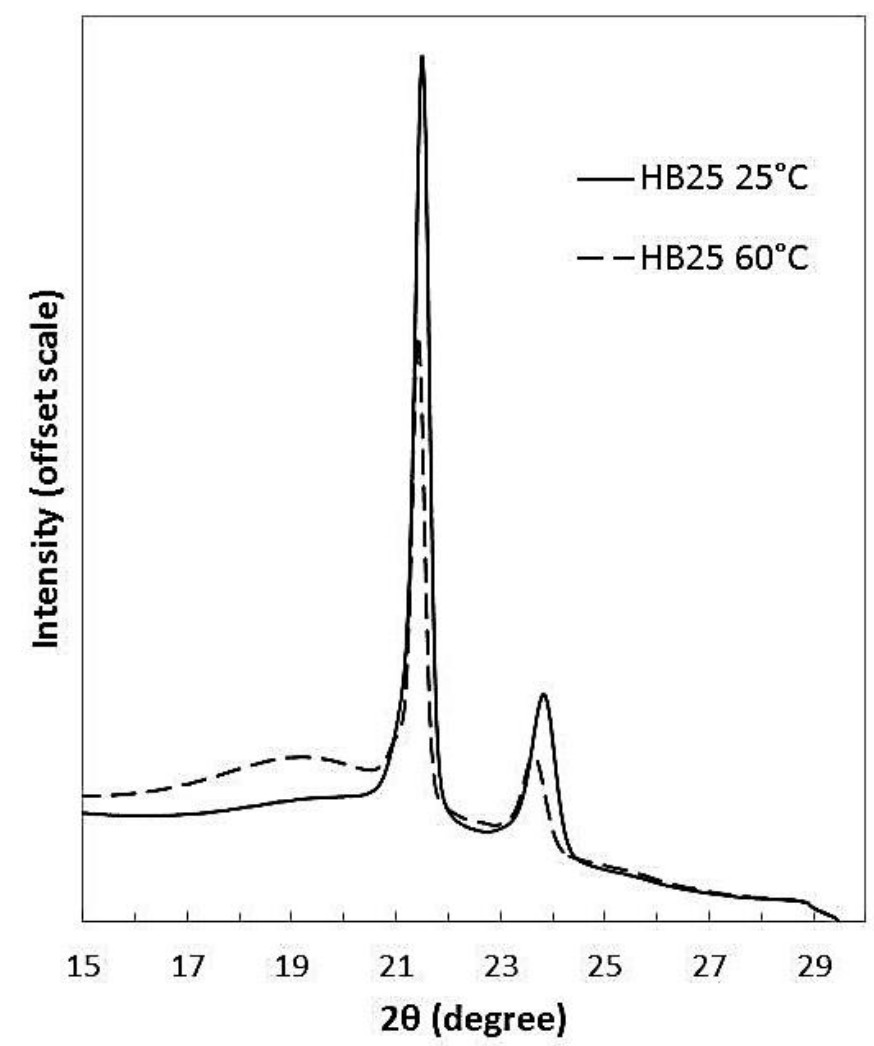

Figure S12- WAXD patterns of $\mathrm{HB} 25$ obtained at $25^{\circ} \mathrm{C}$ and $60^{\circ} \mathrm{C}$. 
Table S2- Scattering angle values and apparent crystallite sizes for HDPE, HB0 and HB25 at different temperatures.

\begin{tabular}{ccccc} 
& $\mathbf{T}\left({ }^{\circ} \mathbf{C}\right)$ & $\mathbf{2 \theta ( 1 1 0 )}\left(\mathbf{(}^{\circ}\right)$ & $\mathbf{2 \theta}(\mathbf{2 0 0})\left(^{\circ}\right)$ & $\begin{array}{c}\text { apparent } \\
\text { crystallite size }^{\mathbf{a}}(\mathbf{n m})\end{array}$ \\
\hline HDPE & 25 & 21.7 & 24.0 & - \\
HB0 & 25 & 21.6 & 24.0 & 28.8 \\
HB25 & 25 & 21.5 & 23.8 & 27.1 \\
HB25 & 60 & 21.4 & 23.7 & 28.8
\end{tabular}

(a) Calculated using Scherrer equation ${ }^{1}$ on the (110) reflection peak

1. P. Scherrer, Göttinger Nachrichten Math. Phys., 1918, 2, 98-100. 